\title{
Participação da Comunidade em Espaços Públicos de Saúde: uma Análise das Conferências Nacionais de Saúde ${ }^{1}$
}

\author{
FRANCINI LUBE GUIZARDI \\ ROSENI PINHEIRO \\ RUBEN ARAUJO DE MATTOS ${ }^{4}$ \\ ANA DÉBORA SANTANA 5 \\ GUSTAVO DA MATTA ${ }^{6}$ \\ MÁRCIA CONSTÂNCIA PINTO ADERNE GOMES
}

\section{RESUMO}

Pautadas pelo princípio de participação da comunidade no Sistema Único de Saúde (SUS), as Conferências Nacionais de Saúde constituem espaços públicos de deliberação coletiva sobre as diretrizes que devem guiar a estruturação e condução do SUS. Tendo em vista que o referido princípio é significado e construído na prática cotidiana e institucional dos atores implicados, saber como a participação tem-se afirmado nessa instância e quais sentidos têm emergido desse processo social é fundamental para que se compreenda tanto sua presença já concreta, como sua capacidade de intervir no SUS. O objetivo deste artigo é analisar, através de relatórios recentes, as Conferências Nacionais de Saúde e a trajetória dos argumentos relativos ao princípio constitucional de participação da comunidade no sistema. Optamos pela análise retórica dos relatórios da VIII, IX, X e XI Conferências, procurando identificar as questões que se colocaram acerca da participação social, desde a instituição do SUS, suas grandes continuidades e os principais deslocamentos argumentativos existentes.

Palavras-chave: Participação social; Conferências Nacionais de Saúde; controle social. 


\section{Introdução}

As Conferências de Saúde ocupam no SUS, desde a promulgação da Lei n. 8.080, de 1990, juntamente com os Conselhos de Saúde, a condição de instância formal de exercício do princípio de participação da comunidade. Sendo uma de suas principais características, esse espaço institucional tem como perspectiva a definição de diretrizes para as políticas de saúde, através da participação dos diferentes atores e segmentos implicados no processo. Nessa acepção, as Conferências de Saúde surgem como instâncias nas quais (pelo menos potencialmente) se abre espaço para que a participação social ocorra na formulação de políticas. Enquanto os conselhos de saúde têm a função de formular estratégias e controlar a execução das políticas, as conferências surgem como uma das arenas nas quais a participação social se antecipa à formulação de políticas, pois se volta para desenhar os princípios, diretrizes e pressupostos que devem orientar todo o processo de formulação de políticas de saúde no período seguinte. As conferências são, desse modo, espaço público de deliberação coletiva sobre as diretrizes que devem guiar a estruturação e condução do SUS, sendo que nelas o princípio da participação da comunidade assume explicitamente um caráter decisório acerca da configuração do sistema.

Não obstante sua importância, há ainda questões a serem respondidas, sobre o significado das conferências na formulação de políticas, sobretudo após a criação do SUS. O princípio de participação da comunidade (que confere legitimidade a esse espaço), apesar de sua centralidade constitucional na organização do SUS, não se encontra conceitualmente definido na Carta Magna, sendo, portanto, significado na prática cotidiana e institucional dos atores que constroem o sistema de saúde. Em face de sua característica construção no processo social, será discutida neste artigo a forma como os temas pertinentes à participação social se apresentam na trajetória das conferências, uma vez que supomos que estes expressem e conduzam (na medida em que objetivam definir diretrizes para as políticas) a materialização desse princípio.

A relevância da discussão reside fundamentalmente no fato de que tais conteúdos sinalizam para a concretização, nesses 16 anos de SUS, de um dos pilares de sua estruturação institucional e do projeto político que o fundamenta: a democratização das políticas de saúde. Essa perspectiva se expressa particularmente na Constituição de 1988, através do referido princípio 
de participação da comunidade no sistema. Veremos de que forma essa temática está presente no relatório das conferências, quais sentidos emergem dela, quais os principais assuntos sobre ela abordados, as questões que se colocaram a seu respeito desde a instituição do SUS, suas grandes continuidades e os principais deslocamentos argumentativos existentes. Pretendemos, com isso, produzir visibilidade para os sentidos e práticas construídos nessa recente experiência de ampla participação popular na definição e condução de políticas públicas no Brasil. Essa experiência representa uma bifurcação histórica relevante, em vista de nossa tradicional cultura política autoritária.

Dessa forma, o objetivo deste trabalho é mapear os discursos e argumentos sobre a participação da comunidade, resultantes do processo social das Conferências Nacionais de Saúde. Esse propósito nos levou a investigar a VIII Conferência Nacional de Saúde, que, apesar de ser anterior ao marco da instituição do SUS, foi escolhida pela peculiaridade de sua influência no desenho do sistema. Analisamos também as três conferências posteriores à Constituição de 1988 - a IX, a X e a XI Conferências Nacionais de Saúde.

O objeto de nosso estudo foi o texto do relatório de cada conferência pesquisada. Ressaltamos nossa opção pela apresentação dos resultados da pesquisa de caráter empírico-documental, em detrimento da revisão da escassa literatura analítica sobre o tema.

A ênfase no relatório final decorre da sua importância como mediador entre a conferência e o cotidiano da formulação de políticas. Uma conferência, em que pese toda a fase de debates prévios, culmina no encontro de seus participantes. Neste, os participantes discutem propostas diversas, examinam diferentes leituras, negociam e disputam entre si posições e, por fim, aprovam certas análises e propostas de diretrizes para as políticas de saúde (e, talvez, certas propostas de políticas de saúde). As propostas aprovadas (uma vez que não necessariamente consensuais) representam as posições majoritárias nesse encontro episódico. Sendo assim, é absolutamente esperado que alguns dos defensores de posições distintas das aprovadas construam estratégias voltadas a atenuar o impacto das resoluções da conferência no cotidiano da formulação de políticas, estratégias que podem incluir, por exemplo, as tentativas de reinterpretar ou de simplesmente ignorar aquelas resoluções.

É esperado também que os defensores das teses aprovadas sigam defendendo-as no cotidiano do processo político, o que freqüentemente envolverá estratégias como evocar sistematicamente aquelas deliberações do plenário. 
Nessa luta política cotidiana, os relatórios finais das conferências são de fundamental importância. Eles têm sido sempre redigidos após a conferência, a partir do conjunto de deliberações aprovadas em plenário, e são o documento chave tanto para difundir para o conjunto da sociedade as deliberações da conferência, como para os que no cotidiano da formulação de política evocam as decisões e os debates nela ocorridos.

Há vários modos de examinar os relatórios finais. Um deles, muito afeito à tradição das análises políticas, procura apreender por detrás do texto as marcas dos embates travados no seu processo de elaboração, das preferências ideológicas dos que lograram ter suas teses aceitas pelo plenário (e por que não dos interesses dos diversos atores participantes?). Esse tipo de leitura busca ultrapassar o texto, para ver numa suposta "profundidade" as características do processo político em curso.

Sem entrar em qualquer reflexão crítica a essa postura, não a adotaremos pelo simples fato de estarmos menos interessados nessa fase preliminar no jogo de interesses que subjaz as Conferências de Saúde, e mais na sua possibilidade de impactar as políticas de saúde. Nesse sentido, e pelas razões indicadas anteriormente, voltamos nossa atenção para a própria "superfície" do texto dos relatórios das conferências, vendo-os como um repertório de enunciados oferecidos aos diversos atores sociais que se engajam na formulação de políticas, sobretudo aos que o fazem na perspectiva de defender os valores que subjazem aquelas deliberações da conferência e, acima de tudo, os valores que subjazem à perspectiva de participação social que as próprias conferências expressam.

Ao tomarmos os relatórios como repertórios de argumentos oferecidos aos atores sociais que participam do processo político, estamos nos aproximando do que poderia ser denominado de estudo da retórica dos relatórios dessas conferências. Seguimos aqui uma perspectiva análoga à adotada por Hirschman (1992) no seu livro A retórica da intransigência - trata-se sobretudo de recolher empiricamente argumentos presentes em certos discursos, comparando-os ao longo do tempo. No caso do presente trabalho, trata-se de reconhecer as continuidades e as mudanças nos argumentos ou teses expressas em sucessivas conferências.

Dessa forma, o intuito do estudo foi identificar a trajetória dos distintos temas e argumentos relacionados ao princípio da participação da comunidade, 
presentes nos relatórios das conferências estudadas. Saber de que maneira a participação tem-se afirmado nessa instância, quais sentidos e significados têm emergido desse processo socia, é fundamental para que se compreenda tanto sua presença já concreta, como sua capacidade de intervir no SUS. Comecemos, então, discutindo o modo como essa temática se encontra presente no relatório da VIII Conferência Nacional de Saúde.

\section{A VIII Conferência Nacional de Saúde: a radicalidade da concepção e do projeto de participação na democratização das políticas de saúde}

A VIII CNS, realizada em 1986, é peculiar no sentido de que nela se coloca, num amplo processo de discussão social, o projeto institucional do Sistema Único de Saúde, forjado na Constituição de 1988. Marco histórico da luta pela democratização das políticas e pela afirmação do direito à saúde, podemos perceber nessa conferência a existência de uma concepção de participação marcada por contornos bastante específicos. Em seu relatório, o tema da participação é apresentado como uma das condições de garantia do direito à saúde, sendo compreendido como "controle do processo de formulação, gestão e avaliação das políticas sociais e econômicas pela população" (Brasil, 1986, p. 4). Note-se que o controle abrange desde a formulação à concretização (gestão e avaliação) das "políticas sociais e econômicas", não sendo dito tratarse especificamente do controle sobre as políticas de saúde. Deste modo, o direito à saúde é apresentado como dependente do controle das políticas estatais. Isso demonstra uma concepção ampliada de política de saúde, na qual esta não é restrita às questões setoriais e abarca em suas implicações a intervenção do Estado na sociedade, sua concretização como políticas públicas.

Assim, a saúde é reafirmada como um "conceito amplo" e o direito à saúde é enfatizado como "conquista social", cujo pleno exercício implica garantir, entre outros pontos, "a participação da população na organização, gestão e controle dos serviços e ações de saúde” (Brasil, 1986, p. 5 - grifo nosso). Podemos observar que a participação da população é apresentada como sendo mais ampla do que o controle, na medida em que envolve todo o processo, a partir da formulação da intervenção no campo. Abrange, com isso, desde seu interior à trajetória da política pública, revelando-se como uma participação na constituição dessa política. Ou seja, com essa concepção de participação, a população adquire condição de sujeito da política de saúde, agente que a 
determina. O controle é apresentado como um de seus aspectos: ela vai da organização ao controle, passando pela gestão, não apenas das ações (o que poderia ser lido como diretrizes programáticas), mas também dos serviços de saúde, nos quais o direito e a política pública a ele relativa ganham materialidade (Brasil, 1986).

Essa concepção de participação coloca a população como protagonista do projeto de construção social do direito à saúde, de tal modo que o relatório da VIII Conferência Nacional de Saúde afirma que, para assegurar esse direito a "toda população brasileira", ou seja, o direito universal à saúde, considera-se imprescindível "estimular a participação da população organizada nos núcleos decisórios" (Brasil, 1986, p. 8). Exemplificando essa afirmação, a análise de conjuntura realizada no relatório sobre a situação da saúde no Brasil é apresentada como decorrente, entre outros aspectos, da "debilidade da organização da sociedade civil". Esta é diretamente associada à "escassa participação popular no processo de formulação e controle das políticas e serviços de saúde" (Brasil, 1986, p. 6). Em suma, como referência central à sua concretização, a participação exige a organização e o acesso às decisões, como forma de garantir o "controle social sobre as ações do Estado" (Brasil, 1986, p. 8). O controle social emerge, então, como efeito da participação, na medida em que esta se caracteriza pela organização e pelo acesso às decisões.

A condição de agente da participação, ou seja, de sujeito da ação, de quem age para a afirmação e construção do direito à saúde, pode ser também exemplificada na necessidade, apresentada no relatório, de se intensificar a "mobilização popular", com a finalidade de garantir na Constituinte o caráter prioritário à saúde (Brasil, 1986, p. 8). Ao relacionar a garantia do direito à saúde na Constituinte com a mobilização e organização popular, o relatório indica novamente sua importância na "conquista social do direito à saúde", demonstrando ser a mobilização estratégia importante de participação. Assinala ainda uma perspectiva em que a participação direta sobressai às formas representativas de intervenção (Brasil, 1986, p. 8). A apreensão da participação da população que assim vai sendo delimitada justifica sua definição como um dos princípios que devem reger o novo Sistema Nacional de Saúde.

Apesar dos exemplos de indicação de ações e da clareza do lugar da participação no projeto de construção do sistema de saúde, o relatório não estabelece de modo consistente a operacionalização das noções apresentadas. Dentre as poucas determinações, é definida a constituição de um novo Conselho 
Nacional de Saúde, composto por representantes dos ministérios da área social (perceba-se que, mais uma vez, não se fala estritamente da saúde quando há menção às políticas públicas), dos governos estaduais e municipais e das entidades civis de caráter nacional, como partidos políticos, centrais sindicais e movimentos populares. É interessante observar nessa composição a ausência da representação de prestadores de serviços, aspecto que sinaliza a compreensão do Conselho Nacional de Saúde como espaço de interlocução do Estado com a sociedade civil, aqui diretamente atrelada à noção de "popular" e à organização política de seus interesses. Isso pode ser corroborado também na constatação de que os profissionais de saúde não se fazem presentes no conselho por meio de sua inserção institucional, mas através de sua organização desde "fora" do sistema de saúde, em sindicatos, partidos políticos ou movimentos sociais.

O objetivo central desse conselho é orientar o desenvolvimento e avaliar o desempenho do Sistema Único de Saúde, sendo sua atribuição definir políticas, orçamento e ações. É possível perceber nessas determinações o caráter constitutivo conferido à participação e sua prevalência na organização desse novo Conselho Nacional de Saúde. Além dele, "deverão ser formados conselhos de saúde em níveis local, municipal, regional e estadual” (Brasil, 1986, p. 18), o que indica preocupação com a descentralização da participação, com sua aproximação a todos os níveis em que há prática decisória e a concretização do sistema de saúde. Reforçando a leitura realizada, sobre os propósitos da descentralização da participação, o relatório expõe "como objetivos desses conselhos a participação plena da sociedade no planejamento, execução e fiscalização dos programas de saúde" (Brasil, 1986, p. 17 - grifo nosso). Tal aspecto é particularmente explicitado na indicação de que "deverá ser garantida a eleição das direções de unidades do sistema de saúde pelos trabalhadores desses locais e pela comunidade atendida" (Brasil, 1986, p. 18).

Também quanto à questão orçamentária, a participação é colocada como estratégia de definição e de concretização de políticas, através da indicação de que "os fundos de saúde, nos diferentes níveis, serão geridos conjuntamente com a participação colegiada de órgãos públicos e da sociedade organizada" (Brasil, 1986, p. 19). Esse aspecto pode ser observado não somente no que tange às políticas de saúde, mas também no que remete às políticas previdenciárias, mesmo porque a concepção de política pública que embasa o relatório não se pauta na delimitação estrita a partir dos setores de intervenção. Nesse sentido, defende-se a diretriz de desvinculação orçamentária da saúde 
em relação à previdência social, sendo dada ênfase à administração dos recursos da previdência pelos trabalhadores, através da determinação de que "o orçamento da Previdência deve ser administrado pelos trabalhadores e utilizado somente para a concessão de benefícios e aposentadorias igualitárias para trabalhadores rurais e urbanos" (Brasil, 1986, p. 20).

\section{IX Conferência Nacional de Saúde: da participação ao controle social}

Em 1992 foi realizada a IX Conferência Nacional de Saúde, marcada por um cenário de intensos obstáculos à concretização do SUS, que podem ser especialmente representados pelo próprio adiamento (por dois anos) de sua realização, bem como pela constante e grave crise no financiamento do sistema (Levcovitz, 1997). Esse contexto é acentuado no relatório, cujo ponto de partida é a demanda do cumprimento e efetivação da lei e a luta política pela reversão da tendência neoliberal no âmbito das políticas públicas. Nele podemos claramente perceber que o projeto de participação que marcou a VIII CNS ganha diferentes contornos, sendo possível observar seu redirecionamento através de uma particular e distinta apreensão do tema. Trata-se, especificamente, da tendência de restrição da participação ao controle social (termo que passa a prevalecer, nomeando a temática), movimento que tende a situá-la externamente no processo de constituição da política, apesar do fato de o controle social ser apresentado como "um componente intrínseco" da democratização da sociedade e do exercício da cidadania.

Essa afirmação pode ser atestada na sutil troca de preposições que ocorre na definição do termo. Deixa-se de utilizar a noção de controle social como uma das dimensões da participação, na medida em que esta supõe e requer um controle do processo, que passa a ser definido como "prática de controle social sobre (e, portanto, desde fora) políticas e atividades envolvidas com a Seguridade Social” (Brasil, 1992, p. 33 - grifo nosso).

Pensadas como exterioridade ao processo político, à vinculação entre produção da política e intervenção estatal, a autonomia e independência frente ao Estado se convertem em objetivos centrais, condição de exercício do controle marcado pela noção de fiscalização. Dessa forma, compreende-se por que a concretização do controle social é associada à manutenção dos foros independentes e autônomos dos movimentos populares, numa argumentação marcada pelo receio de seu atrelamento ou dependência em relação ao Estado. 
Esse argumento é seguido e explicado, no relatório, pela afirmação de que "o controle social não deve ser traduzido apenas em mecanismos formais e sim refletir-se no real poder da população em modificar planos e políticas, não só no campo da saúde" (Brasil, 1992, p. 33 - grifo nosso). Mesmo que a intervenção permaneça como objetivo de atuação dos conselhos, destaca-se nesse trecho a atenuação do poder gestor da participação, ou melhor, do controle social, que não mais tem por objetivo a determinação do processo desde a formulação das políticas à sua fiscalização e acompanhamento, mas o poder de modificar planos e políticas - intervir, portanto, em algo já apresentado ou definido.

Apesar do objetivo de não-contaminação pelo âmbito estatal, permanece como valor diretivo ao controle social a finalidade "transformadora" a ele associado. Nos argumentos que se voltam para esse sentido, não há citação do termo controle social, mas da palavra participação, definida como uma prática voltada para "a transformação da estrutura social" (Brasil, 1992, p. 33). São citados como sujeitos dessa participação, qualificada como "de inegável importância" (já que com sentido e finalidades transformadores), "sindicatos, partidos e demais organizações populares na luta por essas transformações" (Brasil, 1992, p. 33 - grifo nosso). Há dois pontos a serem aqui analisados: 1) a participação, enquanto fazer transformador, é entendida como prática de organizações populares; 2) há uma definição implícita do que sejam "organizações populares", na qual estão incluídos partidos e sindicatos, e não são citadas as organizações de prestadores.

Essas questões evidenciam que, se o controle social é formalmente pertinente a todos os setores implicados, a participação parte de um pressuposto de legitimidade quanto aos interesses que a motivam. Distinção em função da qual a intervenção de outros segmentos que não aqueles abrangidos por essa definição de organização popular se revela desautorizada.

Desenha-se, assim, uma sutil contradição nas definições implícitas de participação e controle social. Se por um lado o controle social é ligado ao "fortalecimento das instâncias públicas como foros legítimos de articulação e resolução dos conflitos de interesse que permeiam as relações entre Estado e a Sociedade" (Brasil, 1992, p. 33) - noção que converge com o objetivo de pactuação de interesses - por outro, o controle social acaba por se chocar com a referida concepção assimétrica de representação democrática que delineia a noção de participação, a partir da qual emergem setores marcados pelo condicionamento da legitimidade de seus interesses. É interessante destacar 
que, posteriormente, a prerrogativa da pactuação, ainda que marcada por essa contradição, foi dissociada da prática do controle social, tornando-se função das comissões intergestores. Isso resultou numa transformação dos conflitos relativos à formulação e organização do SUS em conflitos internos ao Poder Executivo.

Sobressai no relatório a constante preocupação com a existência meramente formal dos conselhos, ponto que está presente em grande parte do texto. Quanto a isso, o relatório afirma especificamente que "no que diz respeito aos conselhos de saúde, tem-se observado o não-cumprimento efetivo da Lei Orgânica de Saúde" (Brasil, 1992, p. 33). Essa avaliação subjaz muitas das deliberações tomadas, voltadas (conforme alguns trechos) para a "constituição dos conselhos segundo a lei”. São explicitadas as diferentes formas observadas de desrespeito à lei referida:

\begin{abstract}
“(...) indicação de representantes dos usuários pelo Poder Executivo, transformação do Secretário de Saúde em presidente nato do Conselho; não implantação dos Conselhos, ou então sua criação sem lhes atribuir caráter deliberativo; depósito dos recursos alocados aos fundos em contas correntes de denominação indicada pela prefeitura; ausência de divulgação das ações realizadas pelos conselhos; desvinculação dos conselhos das Conferências de Saúde; desrespeito ao princípio da paridade entre usuários e demais segmentos" (Brasil, 1992, p. 33).
\end{abstract}

Dados esses obstáculos, o relatório é centrado no estabelecimento de condições de viabilidade para os Conselhos de Saúde, condições que permitam sua independência e autonomia frente ao Poder Executivo. Esse objetivo se converte em diretriz de fortalecimento do controle social, a partir da qual são definidas propostas de caráter operacional, com determinações específicas em relação aos Conselhos de Saúde (Brasil, 1992, p. 34).

Essas indicações convergem para a garantia do dispositivo da representação, no qual os conselhos se baseiam como instância pública de confrontação de interesses. Nessa direção, procuram reafirmá-los e mantê-los como instância exterior e independente do Estado. Alguns pontos "adicionais" procuram garantir a efetividade da representação nos conselhos, voltando-se especificamente para as formas de inserção na atividade de conselheiro. $\mathrm{O}$ relatório fala particularmente da representação dos usuários, apresentando algumas recomendações relativas principalmente à definição do que é e do que 
não é pertinente a essa representação. Os conteúdos relativos ao tema expressam clara preocupação com a presença desse segmento nos conselhos, no sentido de que ela não seja incorporada e anulada pelos demais.

Essas indicações revelam a busca em assegurar objetivos implícitos atrelados aos conselhos: sua função deliberativa, de acompanhamento das políticas e fiscalização da gestão pública, de produção de transparência, de concretização do arcabouço jurídico-institucional do SUS desenhado legalmente, bem como de interlocução entre o sistema de saúde e a sociedade de um modo geral. Percebe-se, com isso, que a temática do funcionamento dos conselhos prevaleceu na discussão sobre o controle social. Em grande parte, esse aspecto se explica pela avaliação de que o arcabouço jurídico-institucional do SUS não havia sido implementado conforme sua definição constitucional.

Frente a essa conjuntura, os Conselhos de Saúde surgiram como referência de garantia de concretização do SUS, desde que corretamente constituídos. Daí o grande investimento em determinações sobre seu funcionamento, composição, atribuições, infra-estrutura etc. As decisões dos Conselhos de Saúde municipais, estaduais e nacional são evocadas freqüentemente como mecanismos de garantia de coerência da implementação do SUS com o projeto que o embasa, "de forma a não se perder de vista o objetivo final do SUS, da melhoria das condições de saúde da população" (Brasil, 1992, p. 16). Isso ocorre, por exemplo, no tocante ao processo de extinção do INAMPS (Brasil, 1992, p. 16); à organização da nova estrutura do gestor nacional (p. 17); à instituição da Carteira Nacional de Saúde (p. 18); e às Comissões Municipais e Estaduais de Reforma Psiquiátrica (p. 19).

As deliberações sobre o repasse de recursos do SUS foram, em sua maioria, associadas ao tema do controle social, sendo caracteristicamente mais específicas, indicando mecanismos e critérios de atuação. Esses aspectos reforçam a compreensão do controle social como "estratégia fundamental" na garantia da implantação do SUS conforme o seu projeto constitucional. No que concerne ao tema, contudo, houve certa particularidade: a intervenção requerida dos diferentes conselhos concentra um caráter deliberativo não observado nos demais campos analisados, divergindo da concepção de externalidade e independência do controle social na constituição de políticas. Sendo assim, por exemplo, é estabelecida como responsabilidade do Conselho Nacional de Saúde (CNS) a definição do "montante global de recursos federais e os percentuais destinados a cada uma das esferas de governo". Com essa deliberação, o CNS 
concentra acentuado poder decisório, apenas restrito frente à indicação de respeito às "atribuições legais estabelecidas e a transferência progressiva de responsabilidade aos governos estaduais e municipais" (Brasil, 1992, p. 26). Ou seja: o exercício das atribuições conferidas não se deve chocar com o arcabouço jurídico-institucional do SUS e com a diretriz de descentralização.

Além dos aspectos já mencionados, encontramos também outra diferenciação frente ao texto da VIII Conferência Nacional de Saúde. Se neste as políticas de saúde são apresentadas amplamente em sua vinculação com as políticas econômicas e sociais, no relatório da IX CNS tal referência não é encontrada, sendo substituída pela ênfase dada à inserção da Saúde no conjunto das políticas de Seguridade Social. A questão do controle social é colocada claramente no âmbito da Seguridade Social, e não diretamente da Saúde, ao mesmo passo em que deixa de ser remetida às demais políticas públicas.

\section{X Conferência Nacional de Saúde: o enrijecimento normativo do controle social}

Uma primeira aproximação permite observar como o relatório da $\mathrm{X}$ CNS, realizada em 1996, se destaca dos demais já em sua forma. Nele não encontramos uma análise da implantação do SUS, ou uma apresentação conceitual dos termos que o compõem, particularmente o controle social. Tal característica nos fará recorrer repetidamente ao texto como forma de exemplificar as noções que o embasam. Isto porque, excetuando a carta de apresentação, o relatório é essencialmente propositivo, sendo, contudo, possível perceber, através dos conteúdos apresentados, os posicionamentos e avaliações que os fundamentam. Mesmo não havendo uma definição de controle social, de seus objetivos e valores, podemos observar a consolidação e o enrijecimento normativo da direção tomada sobre o tema na IX CNS.

Além disso, constata-se que a referência à inserção das políticas de saúde na Seguridade Social é esvaziada do conjunto das proposições, sendo encontrada apenas no tópico específico que trata do tema: "saúde, cidadania e políticas públicas". Nele, a saúde é enfatizada como direito universal de cidadania, a partir da reafirmação de resoluções das conferências anteriores e do texto constitucional, num uso discursivo que parece se restringir a uma reverberação esvaziada de posicionamentos históricos do movimento sanitário.

A única exceção percebida quanto à ausência da Seguridade Social 
nas proposições gerais da conferência sobre as políticas de saúde se refere à garantia de recursos, em relação ao que é proposto: "Os governos Federal, Estaduais e Municipais e os Conselhos de Saúde e de Assistência Social devem assegurar que as verbas arrecadadas para a Seguridade Social não sejam desviadas para outros fins" (Brasil, 1996, p. 40). As proposições situam-se claramente nas fronteiras do setor saúde, extrapolando-as apenas como articulações intersetoriais, pensadas em relação ao tema do controle social como uma estratégia de "aprofundamento do controle social, para democratização do SUS".

De modo geral, a grande e marcante característica do relatório é o movimento em direção a uma intensa normatização das instâncias de controle social, mormente os Conselhos de Saúde. Trata-se da recorrente referência à sua inserção institucional no SUS, que chega a aproximar-se de uma especificação técnica, em que se procura estipular ponto a ponto todas as questões que devem ser apresentadas e aprovadas pelos conselhos, sendo freqüente a menção a datas e prazos estipulados. Esse aspecto faz com que a temática do controle social esteja presente em todo o relatório, sendo associada a grande parte das proposições apresentadas.

Destaca-se que, embora haja constante menção à sua atuação, os conselhos são evocados basicamente como instâncias de acompanhamento e fiscalização, no sentido de que sua intervenção não é exposta como um mecanismo de constituição das políticas que por ele devem passar. Essa análise poderia chocar-se com a forma recorrente com que o termo deliberação é utilizado para caracterizar a atuação dos conselhos. Apesar de sua estreita vinculação com o sentido de prática decisória, o modo como é empregado no texto do relatório demonstra o desgaste desse significado, aproximando essa palavra aos sentidos próximos dos verbos: aprovar, referendar, legitimar. Isto porque, usualmente sua menção é precedida da exposição "do que deve ser deliberado", cuja responsabilidade de apresentação é quase sempre incumbida ao gestor.

"Os Conselhos de Saúde têm poder deliberativo sobre a aplicação dos recursos destinados à área da saúde. Devem aprovar a proposta orçamentária anual e aprovar e acompanhar a execução orçamentária" (Brasil, 1996, p. 49 - grifos nossos).

Há determinações que reforçam o dever de cumprimento das 
deliberações dos conselhos. Isto não garante, contudo, sua inserção no núcleo decisório das políticas, como requisitado e defendido na VIII CNS. Percebe-se que, apesar das afirmações sobre o caráter deliberativo dos conselhos, a produção da política de saúde tende a ser centralizada no Poder Executivo, uma vez que a ele cabe a proposição e apresentação aos conselhos, cuja função seria a "aprovação ou deliberação" das propostas assim colocadas. O lugar de protagonista conferido a esse ator institucional se torna especialmente claro quando se destaca o fato de ele ser evocado como referência de garantia do controle social, particularmente dos Conselhos de Saúde. Afirma-se, por exemplo, que o caráter deliberativo e fiscalizador pretendido para os conselhos deve ser assegurado pelo gestor.

"Os gestores do SUS devem garantir o cumprimento das seguintes regras na composição dos Conselhos da Saúde: a proporcionalidade de: $50 \%$ de usuários, 25\% de trabalhadores de saúde e $25 \%$ de gestores e prestadores" (Brasil, 1996, p. 113).

A posição que os conselhos ocupam em relação às políticas de saúde no relatório consolida a tendência iniciada na IX CNS, mantendo o controle social centrado nas alternativas institucionais legalizadas. Permanece e fortalecese, assim, sua concepção como exterioridade ao processo, seja acompanhandoo, seja fiscalizando-o, ou ainda como instância de sua aprovação-autorização. Tais significados emergem e se justificam no objetivo expresso de garantir, com o controle social, a transparência da gestão.

Em relação ao tema do trabalho em saúde, encontramos uma concepção distinta sobre a participação na definição das políticas públicas. Nela é requisitado um amplo processo de discussão com os setores interessados, como condição para o estabelecimento da Política de Recursos Humanos para a Saúde. O espaço dos Conselhos de Saúde surge como lugar de rediscussão e deliberação permanentes, o que lhe atribui outra inserção no processo.

"O Ministério da Saúde e as Secretarias Estaduais e Municipais de Saúde devem implantar uma Política de Recursos Humanos para a Saúde, através de ampla discussão com os setores sociais interessados. Essa política deve ser permanentemente rediscutida e deliberada com os Conselhos de Saúde, tanto no que se refere ao caráter como no modo de implementação, e deve contemplar principalmente (...)" (Brasil, 1996, p. 227). 
Sentidos dissonantes atribuídos à participação sobressaem particularmente na emergência do tema da gestão participativa, até então inédito nas Conferências de Saúde. O tema é caracterizado pelo objetivo de inserção da participação dos usuários, tanto no planejamento das ações, como na gestão, tendo como valor orientador a democratização do processo. Essa concepção indica uma retomada do sentido constitutivo do princípio da participação da comunidade no SUS. Contudo, tal participação é pensada como exterior aos conselhos, cabendo-lhes, reiteradamente, o lugar de avaliação e deliberação externas.

Apesar da presença dessa outra concepção de participação, prevalece no relatório a noção de controle social como fiscalização e acompanhamento da implantação do SUS. Isso é notório nas atribuições dadas aos Conselhos de Saúde, sobre o financiamento e acompanhamento da distribuição de recursos e da execução orçamentária.

A ênfase na fiscalização e no acompanhamento das políticas, por parte dos Conselhos de Saúde, sinaliza a concepção hegemônica de controle social presente no relatório, na qual ele é pensado como referência externa de garantia da concretização do SUS, conforme determinações constitucionais e infraconstitucionais. Tal sentido torna compreensível o fato de a principal diretriz dos Conselhos de Saúde visar à "autonomia de conselhos e conselheiros de saúde", a partir do objetivo de promover "seu fortalecimento político e a organização independente dos Conselheiros de Saúde" (Brasil, 1996, p. 38).

Assim como na IX CNS, a composição dos Conselhos de Saúde é apresentada como condição para garantir sua independência, o que sugere a persistência de problemas na organização e representatividade dos conselhos. Nesse sentido, coloca-se a necessidade de se promover a reestruturação do Conselho Nacional de Saúde, e de que os conselhos em geral normatizem o processo de escolha e designação dos representantes que os compõem (Brasil, 1996, p. 37).

Além desses pontos, é indicado que os regimentos internos dos Conselhos de Saúde sejam revisados e aprovados pelas respectivas Conferências de Saúde, talvez numa tentativa de garantir sua democratização e a transparência de sua dinâmica, o que pode ser associado a uma provável concentração de poder nos atores institucionais vinculados ao Executivo (Brasil, 1996, p. 37). Também podemos utilizar essa hipótese para explicar a afirmação de que os Conselhos de Saúde devem ter seu presidente eleito entre os seus membros 
(Brasil, 1996, p. 39). Tais temas, assim como a constante reafirmação da relevância pública das atividades dos conselheiros e do fato de que não devem ser remuneradas, já se encontravam presentes na IX CNS. A recorrência desses assuntos faz-nos supor a persistência de certos problemas no funcionamento dos Conselhos de Saúde, problemas que não são aqui enunciados, como o foram no relatório da conferência anterior.

Há um aspecto que merece especial atenção no tema do funcionamento dos conselhos: a proposição de uma Política Nacional de Capacitação de Conselheiros, a ser realizada por meio de cursos e programas de educação continuada, sobre conteúdos considerados indispensáveis para a atuação dos mesmos. Além das atividades de capacitação, são requeridas assessorias permanentes aos Conselhos de Saúde. Ambas as demandas indicam a percepção de despreparo ou da falta de conhecimento dos conselheiros, o que é facilmente compreensível, dada a complexificação técnica do SUS. Supomos, contudo, que essas formulações não se refiram simplesmente ao caráter técnico dos processos do SUS, mas à sua utilização, por profissionais e gestores, como instrumento de poder e de inviabilização da intervenção dos representantes dos demais segmentos no conselho, especialmente dos usuários. Essa análise parece ser corroborada pela indicação de que "os Gestores do SUS, Prestadores de Serviços e Trabalhadores em Saúde devem simplificar o linguajar excessivamente técnico utilizado, para possibilitar melhor compreensão pelos Conselheiros de Saúde e Usuários do SUS" (Brasil, 1996, p. 36).

Outra tendência pode ser destacada no relatório, a qual demonstra extrapolar as fronteiras dos conselhos. Trata-se do movimento de normatização da participação, de extensão acentuada de seus mecanismos e espaços institucionais, numa dinâmica talvez inversamente proporcional aos seus efeitos enquanto estratégia de mobilização. Podemos percebê-la, nos conselhos, pela indicação de criação de diferentes comissões específicas que, todavia, podem ser justificadas pela necessidade de certa especialização para a intervenção nas políticas em questão. Tal tendência emerge mais claramente, porém, na determinação de constituição e implementação de novos mecanismos de participação, como as ouvidorias e serviços de disque-denúncia vinculados aos conselhos; as comissões éticas multiprofissionais; os conselhos distritais e regionais de saúde; entre outros.

A quantidade e a diversidade dos mecanismos propostos sugerem a necessidade de problematização dessa estratégia, de seus efeitos e implicações 
na concretização do princípio constitucional de participação da comunidade. Essa discussão deve abarcar os espaços já institucionalizados, que têm encontrado inúmeros obstáculos à sua efetividade, como o demonstram as próprias indicações do relatório.

\section{XI Conferência Nacional de Saúde: a emergência de outros projetos de participação}

O relatório da XI CNS, realizada em 2000, distingue-se dos demais por suas características argumentativas, pela extensa análise conjuntural apresentada e pela articulação e elaboração discursiva das propostas. Nele, as temáticas da participação e do controle social ocupam lugar de destaque, podendo-se perceber uma diferenciação frente à direção hegemônica que se configurou a partir da IX CNS. Essa direção foi marcada pela redução da participação ao controle social (externo) sobre o Estado e de sua restrição às instâncias instituídas pela legislação do SUS.

Claro indício desse aspecto pode ser percebido através da associação entre a construção do SUS e "um processo de reforma setorial impulsionado por um movimento composto de vários atores sociais", que, ao longo "dessas três últimas décadas", produziu "saberes e práticas políticas, discursivas e paradigmáticas” (Brasil, 2000, p. 13). Em tal afirmação sobressai a relação de protagonismo subentendida entre o movimento social de reforma sanitária e a construção do SUS. Não há aqui a restrição do movimento à noção de controle social. Ao contrário, enfatiza-se sua abrangência, sendo dado destaque aos atores sociais implicados e aos efeitos dessa mobilização, mencionados e valorizados a partir de seus aspectos constitutivos de "saberes e práticas". A participação assume dimensão constitutiva como ação e intervenção no campo social, em virtude do que se podem constatar diversos avanços no Sistema Único de Saúde. Esse fator leva os participantes da Conferência a reconhecerem “(...) que algumas conquistas importantes foram alcançadas, como resultado das intensas mobilizações e forte pressão política exercida sobre a União e o Congresso Nacional" (Brasil, 2000, p. 39). O trecho relatado é marcado pela percepção de que importantes conquistas - especificamente citadas as que se referem à formulação das leis sobre a CPMF e a EC 29/2000 - são fruto da mobilização e pressão política sobre os poderes Executivo e Legislativo nacional. Em outras palavras, são avanços que provêm da movimentação social e não dos mecanismos federativos instituídos que respondem pelo controle do processo 
decisório no âmbito das políticas públicas.

Em relação ao controle social, especificamente, é feita a avaliação de que "(...) houve avanço significativo no controle social do SUS nos últimos anos, como fruto de intensas mobilizações e lutas, o que contribuiu para a melhoria do acesso, da qualidade e da humanização na atenção à saúde" (Brasil, 2000, p. 48 - grifo nosso). É interessante observar que também o controle social é referido em sua condição de prática de participação. Tal associação se impõe através da forma recorrente e enfática, como é destacada a mobilização e as lutas sociais como agentes e instrumentos de transformação e de concretização do projeto da reforma sanitária. Isto fica claro no fato de o avanço relatado - inclusive suas repercussões na organização da assistência - ser diretamente apresentado como resultado de "mobilizações e lutas", e não como conquistas constitucionais ou ações institucionais.

Nesse sentido, a participação é entendida como aspecto central para a efetivação do SUS. Ao contrário do que ocorre nas duas conferências anteriores, essa relação não se constrói nos argumentos apresentados por meio do acompanhamento e da fiscalização do processo em curso nos espaços institucionalizados, mas através de sua intervenção na produção do próprio processo. A noção de participação evocada extrapola os limites e sentidos que vinham delimitando o controle social, sendo assumida como agente de construção e efetivação do SUS. A intervenção dos diferentes atores e segmentos implicados é entendida como fundamental para a concretização de suas diretrizes, não sendo evocada em sua vinculação com os espaços dos conselhos e conferências de saúde. Ainda assim, mesmo não sendo pensada em sua inserção nesses espaços institucionais, há a compreensão de que essa intervenção deve abarcar tanto os aspectos que concernem à formulação, como aqueles pertinentes à fiscalização do SUS.

“Os processos de descentralização, democratização, regionalização e
hierarquização dos serviços de saúde demandam ações de uma ampla rede de
parcerias constituída de cidadãos, usuários, gestores, profissionais, institui-
ções, organizações não-governamentais, conselheiros de saúde e todos aque-
les que podem intervir na formulação e na fiscalização do SUS” (Brasil, 2000,
p. 51).

O lugar conferido à participação não é, portanto, o lugar do controle social em estrito sentido. Isso pode ser especialmente percebido na ausência 
de argumentos que apresentem tal redução, que façam a equivalência entre a participação e as instâncias instituídas no arcabouço jurídico do SUS. Isso não significa, contudo, a ausência da temática e dos problemas percebidos acerca da atuação nesses espaços. Nesse sentido, encontramos exaustiva avaliação conjuntural, que indica claramente a permanência de problemas já sinalizados nas conferências anteriores, e que fala basicamente do não-cumprimento da legislação do SUS no que concerne ao controle social. Os principais aspectos citados foram: o caráter não-deliberativo dos conselhos, sua composição nãoparitária e a falta de respeito às suas decisões (Brasil, 2000). Tais avaliações, contudo, são marcadas por uma leitura divergente da esboçada a partir da IX CNS. Como exemplo disso, analisemos a forma como é realizada particular diferenciação entre "apreciação e deliberação", num uso discursivo que busca enfatizar a existência de distinção entre ambas as ações.

\footnotetext{
"Exigimos que todos os níveis de gestão, federal, estadual e municipal cumpram a legislação e apresentem para apreciação e deliberação dos Conselhos o Plano Anual de Saúde, que deverá sempre ser discutido amplamente com a sociedade, como o caminho de efetivação do SUS" (Brasil, 2000, p. 17 - grifo nosso).
}

No trecho destacado em itálico, há indícios de uma concepção processual e mais constitutiva da participação, que aparece através do advérbio "sempre" e da noção de ampla discussão com a sociedade, não formulada como discussão com e nos conselhos e conferências de saúde. Essa hipótese é corroborada pelo fato de a análise apresentada ser direcionada aos problemas ou impedimentos percebidos quanto à participação dos conselhos na gestão do SUS. Atente-se para o fato de que cabe aos conselhos participar da gestão, e não apenas acompanhar e fiscalizar o sistema, ainda que essas ações estejam inseridas nessa participação. Essa forma de colocar a questão do controle social demonstra um movimento de afastamento de sua perspectiva enquanto exterioridade, e procura acentuar sua inserção no processo de gestão e, portanto, de produção do SUS.

Essa apreensão é destacada na emergência da temática da constituição de sujeitos sociais, diretamente vinculada ao acesso às decisões e ao poder de fiscalização das políticas de saúde. Em outras palavras, há uma discussão direcionada à constituição dos sujeitos dessa participação. A noção de sujeitos sociais procura resgatar a dimensão participativa (tomar parte da ação) do controle social, através da ênfase e do esclarecimento da diferenciação entre 
formulação e fiscalização, como duas ações necessárias.

"O debate a respeito da constituição de sujeitos sociais apontou para a necessidade da sua definição com vistas à formulação e fiscalização de políticas de saúde, entendendo-se por sujeito social cada cidadão individualmente e também os agentes sociais institucionais. No caso da saúde, são sujeitos sociais os conselheiros de saúde e todos aqueles que podem intervir na formulação e na fiscalização do SUS" (Brasil, 2000, p. 50 - grifo nosso).

É interessante destacar que os conselhos não ocupam, ao longo do relatório, o lugar de legitimação de ações definidas pelos gestores. Eles já não aparecem como referência abstrata de garantia da viabilização das recomendações propostas ou do projeto constitucional do SUS. No entanto, a relação com o Poder Executivo é considerada problemática, sendo a falta de autonomia dos conselhos em relação aos gestores um dos principais problemas descritos sobre a atuação dessas instâncias. Questões pertinentes à interferência da cultura política na efetividade dos conselhos também foram bastante citadas. Nesse sentido, além do autoritarismo dos gestores, foram descritos problemas relacionados a práticas clientelistas, à existência de conselhos cartoriais e à ausência de cultura de participação e controle social na sociedade.

São também citados problemas quanto ao funcionamento dos conselhos: a necessidade de sua democratização, de regularização das atividades e de sua composição segundo a lei. Destaca-se a referência à falta de legitimidade de alguns conselhos municipais e as irregularidades na sua composição. A desarticulação dos conselhos com outros conselhos, com a sociedade e com outras instâncias implicadas no controle social foi também referida como um dos obstáculos enfrentados (Brasil, 2000, p. 50).

Além desses fatores, a representatividade dos conselheiros no exercício de suas funções, assim como nas conferências anteriores, emergiu como um impedimento à efetividade dos conselhos, na medida em que impossibilita a representação de interesses que essa instância pressupõe. Sem que os diferentes interesses se apresentem e se afirmem nesse espaço de negociação e pactuação, os conselhos não conseguem garantir a democratização das políticas, expressar e serem permeáveis aos distintos segmentos e setores sociais implicados. São diagnosticados problemas relacionados à comunicação com a sociedade, em certa medida intimamente atrelados às limitações na representatividade dos conselheiros: falta de divulgação, transparência e informações sobre os 
conselhos. São problemas que acabam por cercear suas possibilidades de intervenção e articulação com a sociedade.

Os entraves percebidos nos mecanismos de participação foram diretamente associados a problemas ou à falta de capacitação dos agentes sociais. Nesse sentido, foram reportados especificamente conselheiros de saúde e os próprios gestores, apontando-se para a falta de informações quanto aos princípios e legislação do SUS. Essa deficiência foi percebida tanto nos cidadãos de forma geral, como nas capacitações dos conselheiros (Brasil, 2000, p. 50). Os principais desafios mencionados foram os problemas relacionados ao controle e à fiscalização das atividades do SUS, principalmente aqueles pertinentes à falta de acesso e às dificuldades no uso das informações, assim como às falhas nos mecanismos de acompanhamento e controle de gastos. Nessas questões há particular susceptibilidade a formas de exercícios de poder que, balizadas pelo saber técnico-científico, desautorizam as falas e posições daqueles que não são legitimados por tais conhecimentos, provocando sua exclusão, mesmo nas questões de acompanhamento e fiscalização. Em vista dos obstáculos levantados, os objetivos estabelecidos para os processos de capacitação guiam a construção de "uma formação crítica (política e ideológica), ampliando, assim, a consciência política e a participação popular, objetivando torná-los agentes transformadores da sociedade" (Brasil, 2000, p. 59). Destaca-se nessa formulação o fato de que, assim como na IX CNS, a transformação da sociedade é evocada como valor a ser alcançado com a participação, meta para a qual a capacitação pode fornecer instrumentos de atuação e intervenção aos agentes sociais.

Ponto importante a ser ressaltado no relatório é a inserção das políticas de saúde no conjunto das políticas públicas, definidas como políticas econômicas e sociais. Tal perspectiva se aproxima daquela presente na VIII CNS. É realizada análise da incompatibilidade do projeto do SUS com o modelo econômico vigente, já que os avanços pretendidos "são dificultados pelo fato de que a proposta do SUS - um sistema construído com base em princípios de solidariedade social, que assegura a universalidade do acesso e a integralidade da atenção - não é compatível com o atual modelo econômico" (Brasil, 2000, p. 22). Note-se que "as lutas de importantes segmentos da sociedade civil" e a reversão de um padrão de intervenção no âmbito econômico são considerados centrais à reorientação dessas políticas, sendo tais ações diretamente vinculadas à implementação do SUS. 
Desse modo, pode-se observar a tentativa de refazer a vinculação entre as políticas de saúde e a Seguridade Social, por meio do resgate desse conceito, o que se espera ser feito com a integração das políticas da área e com a destinação de recursos de todas as contribuições sociais para a área da saúde. Tal perspectiva demonstra, entretanto, que o "resgate do conceito de seguridade social" é pensado através das fronteiras do setor saúde, como uma "garantia dos recursos necessários" e não como uma forma de integração na construção do direito que embasa tal conceito. Assim, podemos constatar que o resgate pretendido ocorre com o fortalecimento da diferenciação da saúde das demais políticas de seguridade social, contrariando inclusive a diretriz apresentada na VIII CNS, que estabelecia que os recursos deveriam ser desvinculados de contribuições previdenciárias, as quais custeariam somente a concessão de benefícios e aposentadorias igualitárias para trabalhadores rurais e urbanos.

\section{Considerações Finais}

Como foi possível observar, os temas relativos ao princípio da participação da comunidade apresentaram, ao longo dos relatórios pesquisados, configurações bem delimitadas, algumas marcadas por importantes deslocamentos de sentidos. No relatório da VIII Conferência Nacional de Saúde, a participação é pensada a partir de sua inserção na constituição da política de saúde, como sujeito de sua determinação e do acompanhamento e fiscalização de seu respectivo processo, em todos os níveis do sistema. Nesse sentido, o controle social emerge como efeito dessa participação, que tem por objeto não estritamente o setor saúde, mas a compreensão desse campo em suas implicações recíprocas com as políticas sociais e econômicas.

Ao longo da IX Conferência Nacional de Saúde, nos diferentes pontos abordados sobre o controle social, é possível constatar o redirecionamento do projeto de participação exposto na conferência anterior. Esse movimento é marcado pela tendência de fechamento desse projeto sobre os espaços legalmente institucionalizados, a partir da noção de controle externo ao processo de constituição das políticas de saúde. Não se trata, com isso, de garantir ou lutar por uma participação interna, sujeito de ação da concretização do SUS, mas de garantir o cumprimento das conquistas constitucionais, nas quais o caráter constitutivo não é afirmado. Cabe a ela, sobretudo, o lugar de exterioridade e de autonomia que garante a eficácia do objetivo de acompanhamento e fiscalização da implementação do SUS. Isso pode ser observado na presença 
hegemônica dos conteúdos relativos aos Conselhos de Saúde, na tentativa de garantir a independência e a perspectiva de fiscalização em seu funcionamento. Apesar da permanência do caráter decisório dos conselhos na destinação e determinação da gestão dos recursos, nos demais tópicos esse aspecto não é observado, prevalecendo a tendência exposta, ainda que conceitualmente referida ao valor transformador do controle social.

Na X Conferência Nacional de Saúde, esse movimento é consolidado, reforçando a redução da noção de participação à prática (externa) do controle social. Apesar da emergência do tema da gestão participativa, das peculiaridades percebidas quanto à política de recursos humanos, e do grande número de novos mecanismos de participação propostos, o relatório da X CNS é marcado pela consolidação do controle social como prática externa de acompanhamento e fiscalização do SUS, que the confere legitimidade e garante coerência com o projeto inscrito na Constituição.

Em contrapartida, a presença da participação/controle social no relatório da XI CNS indica uma diferenciação do referencial esboçado a partir da IX CNS. No relatório, a participação começa a se desenhar como prática decisória, que não equivale à existência dos espaços institucionalizados no arcabouço jurídico-institucional do SUS, embora esteja clara a compreensão de que esse projeto de participação deve fundamentá-los. Como hipótese explicativa desse movimento, podemos supor a persistência dos obstáculos referidos ao controle social, não obstante sua institucionalização e expansão quantitativa. Talvez tenha emergido o questionamento, em grande medida propiciado pelas questões trazidas nesse cotidiano institucional, sobre os limites dessa forma de participação, as restrições do não-acesso concreto às decisões. Provavelmente, as fronteiras impostas ao movimento daqueles que se mobilizam na construção do direito à saúde - construção incessante de realidades e perspectivas coletivas - tenha forçado e provocado o esgarçamento da concepção legal de participação/ controle social. Talvez as transformações que começam a esboçar-se na XI CNS apontem para a organização de outros projetos de participação, muitos dos quais já ensaiados ou mesmo configurados nas práticas de diferentes atores sociais. É necessário rediscutir os espaços institucionais existentes, principalmente no que tange à sua permeabilidade concreta, ao "tomar parte" da produção do SUS pela comunidade. Embora essas hipóteses apenas o processo social e as próximas Conferências Nacionais de Saúde poderão responder, talvez o próprio movimento de formulá-las seja um passo necessário à efetivação do SUS e do projeto que o fundamenta. Sem essas indagações, corremos o risco de endossar 
concepções contrárias à democratização das políticas de saúde, atualizando, assim, relações de poder que julgamos combater.

\section{Referências}

CONFERÊNCIA NACIONAL DE SAÚDE, 8., 1986, Brasília. Relatório final. Ministério da Saúde: Brasília, 1986.

CONFERÊNCIA NACIONAL DE SAÚDE, 9., 1992, Brasília. Relatório final: municipalização é o caminho. Ministério da Saúde: Brasília, 1992.

CONFERÊNCIA NACIONAL DE SAÚDE, 10., 1996, Brasília. Relatório final: SUS - construindo um modelo de atenção à saúde para a qualidade de vida. Ministério da Saúde: Brasília, 1996.

CONFERÊNCIA NACIONAL DE SAÚDE, 11., 2000, Brasília. Relatório final. Brasília, 2000.

HIRSCHMAN, A.O. A retórica da intransigência: perversidade, futilidade, ameaça. São Paulo: Companhia das Letras, 1992.

LEVCOVTIZ, E. Transição $x$ consolidação: o dilema estratégico da construção do SUS. 1997. Tese (Doutorado em Saúde Coletiva) - Programa de Pós-graduação em Saúde Coletiva, Instituto de Medicina Social, Universidade do Estado do Rio de Janeiro, Rio de Janeiro, 1997.

\section{NOTAS}

\footnotetext{
${ }^{1}$ Os resultados aqui apresentados constituem um dos eixos de análise da pesquisa "(Re)Visitando as últimas Conferências Nacionais de Saúde: um estudo sobre como alguns temas foram tratados nas Conferências Nacionais de Saúde", orientada pelo professor Ruben Araujo de Mattos. Projeto de cunho exploratório guiado pelo objetivo de analisar as práticas de controle social na formulação de políticas, a pesquisa foi financiada pela Organização Pan-Americana de Saúde (OPAS), com o apoio do Ministério da Saúde, por meio da Secretaria de Gestão Participativa. Agradecemos, em particular, à Dra. Ana Maria Costa, cuja colaboração tornou possível este estudo.

${ }^{2}$ Psicóloga, doutoranda em Saúde Coletiva pelo Instituto de Medicina Social da UERJ.

${ }^{3}$ Professora visitante do Instituto de Medicina Social da UERJ; doutora em Saúde Coletiva.

${ }^{4}$ Professor adjunto do Instituto de Medicina Social da UERJ; doutor em Saúde Coletiva.

${ }^{5}$ Médica, mestranda em Saúde Coletiva pelo Instituto de Medicina Social da UERJ.

${ }^{6}$ Psicólogo, doutorando em Saúde Coletiva pelo Instituto de Medicina Social da UERJ.

${ }^{7}$ Médica, mestranda em Saúde Coletiva pelo Instituto de Medicina Social da UERJ.
} 
Public Participation in Health: an Analysis of the National Health Conferences in Brazil

Based on the principle of community participation in the Unified National Health System (SUS), the National Health Conferences in Brazil have served as public spaces for collective decision-making on the guidelines for the organization and implementation of the SUS. Given that the community participation principle gains meaning and substance in the daily and institutional practices of the various stakeholders, it is crucial to know how popular participation has materialized and the meanings that have emerged from this social process in order to understand both its actual presence and its capacity to impact the construction and consolidation of the National Health System. The article thus draws on the reports of the recent National Health Conferences to analyze the country's experience with the principle of community participation in the System (as provided by the 1988 Constitution). We performed a discourse analysis of the reports from the $8^{\text {th }}$, $9^{\text {th }}, 10^{\text {th }}$, and $11^{\text {th }}$ National Conferences, seeking to identify social participation issues since the National Health System was implemented, including both the issues that traversed all four Conferences as well the main argumentative shifts that occurred during the same period.

Key words: Social participation; National Health Conferences; social control.

Recebido em: 16/04/2004.

Aprovado em: 03/05/2004. 